\title{
Comparative study of platelet indices in coronary artery diseases
}

\author{
Gururajaprasad. C1,", Ishita Maheshkumar Kaneria², Akkamahadevi. P³, Manjappa Mahadevappa ${ }^{4}$ \\ ${ }^{\mathbf{1}}$ Associate Professor, ${ }^{2}$ Post Graduate, ${ }^{3}$ Professor and HOD, ${ }^{4}$ Assistant Professor, ${ }^{1,2}$ Dept. of Pathology, ${ }^{3}$ Dept. of Emergency \\ Medicine, ${ }^{4}$ Dept. of Cardiology, J.S.S Medical College, J.S.S. University, Mysore, Karnataka, India
}

*Corresponding Author: Gururajaprasad. C

Email: geepee111@yahoo.co.in

Received: $14^{\text {th }}$ June, 2018

Accepted: $15^{\text {th }}$ July, 2018

\begin{abstract}
Introduction: With urbanization and increase in sedentary lifestyle, prevalence of CAD (Coronary artery disease) is looming large as the new epidemic afflicting Indians. Altered platelet morphology and functions have been linked with the formation and propagation of thrombotic event. Platelet indices (Mean platelet volume - MPV, Platelet distribution width - PDW, Platelet large cell ratio - PLCR) are determinants of platelet functionality.

Aims and Objectives: 1 . To study platelet indices (MPV, PDW, P-LCR) in CAD; 2. To compare platelet indices in patients with myocardial infarction, stable CAD and control population.

Material and Methods: A comparative and prospective study was conducted on 100 patients each of MI \& stable CAD on antiplatelet therapy and 100 age and sex matched healthy individuals as controls. Platelet indices were measured using an Automated Blood Counter SYSMEX XN-1000. Troponin T and CK-MB levels were collected from clinical data in MI cases.

Results: Platelet indices were significantly higher in MI patients in comparison to stable CAD and control groups. Stable CAD patients also showed significantly higher platelet indices in comparison to control groups. ( $\mathrm{p}$ value $<0.001$ )

Conclusion: The present study showed a significantly higher MPV, PDW and P-LCR in CAD patients in comparison to control group. Among CAD patients, MI patients had significantly higher platelet indices than stable CAD patients. Hence platelet indices can be used as simple and cost effective predictive parameters to predict CAD. Their use in a risk stratification system to predict MI and in response to intervention are worthy of consideration.
\end{abstract}

Keywords: Coronary artery diseases, Platelet indices, Mean platelet volume, Platelet distribution width, Platelet large cell ratio.

\section{Introduction}

The leading cause of mortality and morbidity in the world is Coronary artery disease (C.A.D). The commonest causes of mortality in patients with CAD are acute coronary syndromes (ACS), which encompass unstable angina (UA), non-ST-segment elevation myocardial infarction (NSTEMI) and ST-segment elevation myocardial infarction (STEMI). Indians have a very high incidence of the prevalence of CAD and the incidence of ACS. ${ }^{1-5}$ The highest burden of CAD in the world is seen in India. ${ }^{6}$ In Indians, the rising incidence of CAD may be related to the changes in the lifestyle, the westernization of the food practices, the increasing prevalence of diabetes mellitus and probably genetic factors. $^{7}$

Pathogenesis of CAD is attributed to the altered platelet morphology and functions. Hyperactivity of platelets has an important role in the initiation of atherosclerotic lesions and coronary thrombogenesis. As compared to smaller sized platelets, larger platelets are more active enzymatically and metabolically and have higher thrombotic ability. ${ }^{8,9}$

The Platelet indices (Platelet count, Mean platelet volume - MPV, Platelet distribution width - PDW and Platelet large cell ratio - PLCR) determine platelet function. An increased mean platelet volume (MPV) and platelet distribution width (PDW) have been found to be important contributory factors causing thromboembolism. ${ }^{8}$
On routine hematological analysis, larger platelets can be identified and could possibly benefit from preventive/therapeutic treatment.

Coronary artery disease is such a huge public health problem and platelet volume indices are an important, simple and cost-effective tool in predicting the possibility of coronary artery disease, with simple hematological analysis, possible preventive/therapeutic measures can be taken. This study is aimed at finding a link between $\mathrm{CAD}$ and platelet indices.

\section{Objectives of the Study}

1. To study platelet indices (Platelet count, MPV, PDW, P-LCR) in coronary artery diseases.

2. To compare platelet indices in patients with myocardial infarction, stable $\mathrm{CAD}$ and control population.

\section{Materials and Methods}

Source of Data: The present study was undertaken in the Department of Pathology, JSS Medical College and Hospital, Mysore.

\section{Method of Collection of Data:}

1. Study period: October 2015 to September 2017.

2. Study design: Analytical study

\section{Sample size and Study Subjects:}

Group 1: 100 Myocardial infarction patients not on antiplatelet treatment. 
Group 2: 100 Stable CAD patients on antiplatelet treatment.

Group 3: 100 age and sex matched healthy individuals.

Inclusion Criteria: Diagnosed cases of coronary artery diseases.

Exclusion Criteria: Patients with a history of renal disease or of past coronary intervention or coronary arterial bypass grafting, inflammatory rheumatic disease, chronic obstructive pulmonary disease and taking oral anticoagulants were excluded. Myocardial infarction patients pretreated or loaded with antiplatelet drugs were excluded.

Method of Collection of Data:

1. Data collection was done in a predesigned proforma.

2. Venous blood samples were collected in a vacutainer containing di-potassium EDTA and processed within 2 hours of sample collection.

3. Platelet indices (PC, MPV, PDW, P-LCR) were measured in cases and control groups using an Automatic Blood Counter (SYSMEX, XN-1000)

4. Serum Troponin $\mathrm{T}$ and CK-MB levels of MI patients were collected from clinical data.

\section{Statistical Methods}

Descriptive statistics such as numbers and percentages were used to describe categorical variables. Mean and standard deviations were used to describe continuous variables like platelet count, MPV, PDW and P-LCR. Independent sample t-test was applied to find out the significant difference in platelet count, MPV, PDW and P-LCR between the cases and controls. Pearson's correlation was used to analyse association between different variables. Statistical significance was determined at $5 \%$ level of significance (i.e. $<0.05$ is significant). Statistical analysis was done using Statistical package for social sciences (SPSS version 22) software. Microsoft word and Excel have been used to generate graphs, tables etc.

Investigations

1. Complete blood count/ complete hemogram

2. Serum Troponin $T$

3. Serum CK-MB

\section{Results}

The present study included 100 cases each of myocardial infarction, stable CAD diagnosed at JSS hospital, Mysore from August 2015 to September 2017. Platelet indices, ECG and serum markers were recorded in a proforma. The details were then transcribed into master chart and analyzed.

Age Distribution: Age of myocardial infarction patients ranged from 32 years to 85 years with mean age of $64.2 \pm 11.52$ years. Age of stable CAD patients ranged from 25 years to 81 years with mean age of 61.7 \pm 11.88 years. Age of controls ranged from 52 years to 89 years with mean age of $67.6 \pm 10.71$.
Sex Distribution: Out of 100 MI cases, number of males and females were 64 and 36, respectively. Out of 100 stable CAD cases, number of males and females were 67 and 33 respectively. Controls had 59 males and 41 females.

Subtypes of Myocardial Infarction Cases: Out of 100 MI cases, 78 were ST elevation MI (STEMI) and 22 were Non-ST elevation MI (NSTEMI).

Serum Markers in Myocardial Infarction Patients: Serum Troponin $\mathrm{T}$ and CK-M levels were available for all MI cases. Mean Troponin T and CK-MB levels were $1.16 \mathrm{ng} / \mathrm{ml}$ and $28.9 \mathrm{ng} / \mathrm{ml}$, respectively. Mean CK-MB level was higher in NSTEMI $(38.51 \mathrm{ng} / \mathrm{ml})$ than STEMI $(26.19 \mathrm{ng} / \mathrm{ml})$. However, there was no significant difference between CK-MB levels in these two groups. $(\mathrm{p}>0.05)$.

Mean Troponin T levels of STEMI and NSTEMI were almost similar i.e. 1.15 and $1.17 \mathrm{ng} / \mathrm{ml}$, respectively with no significant difference $(p>0.05)$.

Platelet Count in all 3 Study Groups: Mean platelet count of MI, stable CAD and controls were $2.78 \pm 0.77$, $3.32 \pm 0.86$ and $2.9 \pm 0.65\left(10^{6} / \mathrm{L}\right)$, respectively with no significant difference ( $\mathrm{p}$ value -0.41 ).

MPV in all 3 Study Groups: Mean MPV of MI, stable $\mathrm{CAD}$ and controls were $10.5 \pm 0.76,10.2 \pm 0.87,9.4 \pm$ $0.7 \mathrm{fL}$, respectively. There was a significant difference between MPV of these groups ( $p<0.001$ ) with highest mean MPV being of MI group.

PDW in all 3 Study Groups: Mean PDW of MI, stable CAD and controls were $12.1 \pm 1.68,11.8 \pm 2.22$ and $9.8 \pm 1.4 \mathrm{fL}$, respectively. PDW was found to be significantly higher in MI group compared with stable CAD and control group, $\mathrm{p}<0.0001$ ).

P-LCR in all 3 Study Groups: Mean P-LCR in MI, stable CAD and controls were $28.3 \pm 5.87,26.6 \pm 7.22$ and $20.1 \pm 5.84 \%$, respectively. P-LCR was significantly higher in MI group in comparison to stable CAD and control group ( $\mathrm{p}<0.0001)$.

Platelet Indices in MI Subtypes: STEMI and NSTEMI cases had mean platelet count of $2.8 \pm 0.77$ and $2.9 \pm 0.8$, mean MPV of $10.5 \pm 0.74$ and $10.58 \pm$ 0.85 , mean PDW of $12.1 \pm 1.68$ and $12.18 \pm 1.76$ and mean P-LCR of $28.68 \pm 6.07$ and $27.58 \pm 5.12$, respectively. However, there was no significant difference between all platelet indices of STEMI and NSTEMI cases.

Platelet indices and Serum Markers of MI: There was no significant correlation of platelet indices with serum Troponin $\mathrm{T}$ and CK-MB levels. ( $\mathrm{p}>0.05)$.

\section{Discussion}

CAD is the most leading cause of mortality and morbidity in India ${ }^{4}$ and has highest burden of CAD in the world. ${ }^{6}$ The increasing incidence of CAD amongst Indians may be related to the changes in the lifestyle, the westernization of the food practices, the increasing prevalence of diabetes mellitus and probably genetic factors. $^{7}$ 
Pathogenesis of CAD is linked with the altered platelet morphology and functions. The platelets become hyperactive and larger in size when they come in contact with ruptured plaque. These larger platelets are more active metabolically and enzymatically and have higher thrombotic ability as compared to small sized platelets because of higher production of thromboxane A2. ${ }^{8,9}$

In addition to generation of thromboxane A2, activation of platelets leads to conformational change in GP IIb/IIIa receptors. These receptors develop a high affinity for fibrinogen. Multivalent molecule Fibrinogen can bind to two different platelets at a time and results in platelet cross-linking and aggregation. ${ }^{10,17}$ Hence an increase in platelet consumption at the site of the atherosclerotic plaque occurs which causes larger platelets to be released from the bone marrow. ${ }^{18,19}$

At the site of plaque, the thrombus composed of platelet aggregates and fibrin strands traps red blood cells and thus can reduce coronary blood flow, leading to the clinical manifestations of myocardial ischemia. ${ }^{10}$

Total or partial thrombosis superimposed on a disrupted plaque is a core factor in acute coronary syndromes. ${ }^{11}$ Platelet reactivity is most important in the formation and propagation of intracoronary thrombus mainly due to their proinflammatory effects by recruiting white blood cells (WBC) at vascular injury sites, thus directly increasing the plaque burden. ${ }^{20-23}$

The larger platelets can be identified in routine hematological analysis by platelet volume indices (Platelet count, Mean platelet volume, Platelet distribution width and Platelet large cell ratio). ${ }^{8}$

The present study was conducted to determine the relationship of platelet indices with $\mathrm{CAD}$ and to compare the platelet indices in myocardial infarction, stable CAD and control population. 100 cases of each MI, stable CAD cases and age and sex matched controls were studied in present study.

\section{Age Distribution}

1. Myocardial Infarction Cases: Majority of patients fell into age group of 61 years to 70 years with mean age being 64.2 yrs.

2. Stable CAD Cases: Majority of patients were in the age group of 61 years to 70 years with mean age being 61.7 years. This age distribution of MI and stable CAD show that with increase in age, the risk of developing CAD increases. This may be due to age dependent increase in risk factors like diabetes mellitus, hypertension and hyperlipidemia. Sex Distribution: A male preponderance was observed in patients with CAD with the male to female ratio being 1.8:1 \& 2:1 among the patients with M.I and stable CAD respectively. This shows males are more prone to the development of CAD than females.

MI Subtypes: Among 100 M.I patients, 78 were STEMI and 22 were NSTEMI. Many studies have found similar results. ${ }^{20,68,70,74}$ However, Ahmed et all ${ }^{86}$ found more NSTEMI cases than STEMI cases.

Serum markers of MI: Mean Troponin T and CK-MB levels were $1.16 \mathrm{ng} / \mathrm{ml}$ and $28.9 \mathrm{ng} / \mathrm{ml}$, respectively. When the NSTEMI \& STEMI subgroups were compared, there were no significant differences in the levels of Troponin T \& CK-MB which correlated with the study conducted by Orak et al. ${ }^{91}$

Platelet count and CAD: Mean platelet count was seen to be lowest in MI patients(2.78 \pm 0.77$)$ in comparison to the stable CAD patients which probably is due to immediate increased consumption of platelets at the site of plaque rupture. ${ }^{72}$ But there was no significant difference among mean platelet count of all the 3 groups. This finding was supported by Khode et al ${ }^{81}$ $2.89 \pm 1.04)$ and Sharma et $\mathrm{al}^{18}(2.63 \pm 0.33)$ but it was in contrast to studies conducted by Khandekar et al ${ }^{19}$ $(2.32 \pm 0.84)$, Ranjith et $\mathrm{al}^{72}(2.01 \pm 0.13)$ and Amraotkar et $\mathrm{al}^{70}(2.14 \pm 0.69)$.

MPV and CAD: A significant difference was seen in the mean MPV of MI and stable CAD (10.45 \pm 0.76 and $10.21 \pm 0.87$, respectively). This was further supported by Amraotkar et al, ${ }^{70}$ Khode et $\mathrm{al}^{81}$ and Ranjith et al. ${ }^{72}$ An Increase MPV seen during MI may be due to increased platelet reactivity, which in turn increases platelet surface expression of IIb/IIIa receptors and $\mathrm{P}$ selectin proteins. According to our study results, MPV was higher in patients with stable CAD compared with the normal population. A possible explanation for an increased platelet volume and MPV is an increased activity of platelets and activation of the coagulation cascade due to enhanced vasoconstrictor substances. $^{72}$

Table 1

\begin{tabular}{|c|c|c|c|c|}
\hline \multirow[t]{2}{*}{ Study } & \multirow[t]{2}{*}{ Year } & \multicolumn{2}{|c|}{ Mean MPV (fL) } & P value \\
\hline & & MI & SCAD & \\
\hline Khandekar et $\mathrm{al}^{19}$ & 2009 & $10.43 \pm 1.03$ & $9.37 \pm 0.99$ & $<0.001$ \\
\hline Khode et $\mathrm{al}^{81}$ & 2012 & $9.65 \pm 0.9$ & $9.38 \pm 0.8$ & 0.025 \\
\hline Ranjith et al ${ }^{72}$ & 2015 & $10.97 \pm 0.58$ & $10.03 \pm 0.23$ & $<0.001$ \\
\hline Sharma et al ${ }^{18}$ & 2016 & $10.29 \pm 1.12$ & $9.19 \pm 0.62$ & $<0.001$ \\
\hline Amraotkar et $\mathrm{al}^{70}$ & 2017 & $9.18 \pm 1.21$ & $8.13 \pm 0.66$ & 0.003 \\
\hline Present study & 2017 & $10.45 \pm 0.76$ & $10.21 \pm 0.87$ & 0.000 \\
\hline
\end{tabular}


PDW and CAD: Mean PDW of MI and stable CAD were $12.06 \pm 1.69$ and $11.77 \pm 2.22$, respectively. This is in concordance with studies conducted by Khandekar et $a l,{ }^{19}$ Ranjith et $\mathrm{al}^{72}$ and Sharma et al. ${ }^{18}$ However, Khode et $\mathrm{al}^{81}$ did not find any significant difference in
PDW among these groups. It is argued that this platelet volume distribution provides a cause for the prethrombotic state in IHD. So, considering that PDW is an index of platelet heterogeneity, this might explain the above witnessed increase in MI. ${ }^{72}$

Table 2

\begin{tabular}{|c|c|c|c|c|}
\hline \multirow[t]{2}{*}{ Study } & \multirow[t]{2}{*}{ Year } & \multicolumn{2}{|c|}{ Mean PDW (fL) } & \multirow[t]{2}{*}{ P value } \\
\hline & & MI & SCAD & \\
\hline Khandekar et al ${ }^{19}$ & 2009 & $13.19 \pm 2.34$ & $11.35 \pm 1.95$ & $<0.001$ \\
\hline Khode et al ${ }^{81}$ & 2012 & $10.84 \pm 2.2$ & $10.65 \pm 1.7$ & 0.376 \\
\hline Ranjith et al ${ }^{72}$ & 2015 & $14.63 \pm 0.64$ & $12.43 \pm 0.62$ & $<0.001$ \\
\hline Sharma et al ${ }^{18}$ & 2016 & $15.11 \pm 0.88$ & $13.25 \pm 0.44$ & $<0.001$ \\
\hline Present study & 2017 & $12.06 \pm 1.69$ & $11.77 \pm 2.22$ & 0.000 \\
\hline
\end{tabular}

P-LCR and CAD: Mean P-LCR of MI and stable CAD were $28.32 \pm 5.87$ and $26.59 \pm 7.22$, respectively difference is significant. This was further supported by
Khandekar et al ${ }^{19}$ and Ranjith et al. ${ }^{72}$ However, Khode et $\mathrm{a}^{81}$ did not find any significant difference in P-LCR among these groups.

Table 3

\begin{tabular}{|l|c|c|c|c|}
\hline \multirow{2}{*}{ Study } & \multirow{2}{*}{ Year } & \multicolumn{2}{|c|}{ Mean P-LCR (\%) } & \multirow{2}{*}{ P value } \\
\cline { 3 - 4 } & & MI & SCAD & \\
\hline Khandekar et al $^{19}$ & 2009 & $29.4 \pm 7.38$ & $22.55 \pm 6.65$ & $<0.001$ \\
\hline Khode et al $^{81}$ & 2012 & $21.58 \pm 6$ & $20.92 \pm 6.4$ & 0.315 \\
\hline Ranjith et al $^{72}$ & 2015 & $32.23 \pm 1.94$ & $26.77 \pm 1.08$ & $<0.001$ \\
\hline Present study & $\mathbf{2 0 1 7}$ & $\mathbf{2 8 . 3 2} \pm \mathbf{5 . 8 7}$ & $\mathbf{2 6 . 5 9} \pm \mathbf{7 . 2 2}$ & $\mathbf{0 . 0 0 0}$ \\
\hline
\end{tabular}

Platelet Count and MI Subgroups: The mean platelet count of STEMI and NSTEMI were noted to be $2.81 \pm$ 0.77 and $2.89 \pm 0.79$, respectively with no significant difference. ( $p$ value - 0.65). This was in concordance with Salim et al ${ }^{87}$ and Rifat et al ${ }^{89}$
MPV and MI Subgroups: Mean MPV of STEMI and NSTEMI patients were $10.46 \pm 0.74$ and $10.45 \pm 0.85$, respectively with no significant difference ( $\mathrm{p}$ value 0.95 ). This finding was further supported by Salim et al, ${ }^{87}$ Manchanda et al. ${ }^{20}$

Table 4

\begin{tabular}{|l|c|c|c|c|}
\hline \multicolumn{1}{|c|}{ Study } & \multirow{2}{*}{ Year } & \multicolumn{2}{c|}{ Mean MPV (fL) } & P value \\
\cline { 3 - 5 } & & STEMI & NSTEMI & \\
\hline Rifat et al $^{89}$ & 2011 & $8.7 \pm 1$ & $7.9 \pm 0.7$ & $<0.001$ \\
\hline Salim et al & & $10.9 \pm 0.7$ & $10.7 \pm 0.6$ & 0.32 \\
\hline Manchanda et al $^{20}$ & 2013 & $9.67 \pm 0.82$ & $9.54 \pm 0.76$ & $>0.05$ \\
\hline Ahmed H et al $^{88}$ & 2015 & $10.32 \pm 0.78$ & $9.22 \pm 0.53$ & $<0.05$ \\
\hline Patil et al $^{90}$ & 2017 & $10.48 \pm 1.42$ & $9.73 \pm 1.15$ & 0.001 \\
\hline Present study & $\mathbf{2 0 1 7}$ & $\mathbf{1 0 . 4 6} \pm \mathbf{0 . 7 4}$ & $\mathbf{1 0 . 4 5} \pm \mathbf{0 . 8 5}$ & $\mathbf{0 . 9 5}$ \\
\hline
\end{tabular}

PDW and MI Subgroups: Mean PDW of STEMI and NSTEMI were noted to be $12.07 \pm 1.68$ and $12.05 \pm$ 1.76, respectively. However, no significant difference was noted in mean PDW of these two groups which was in concordance with Salim et $\mathrm{al}^{87}$ and Manchanda et al. ${ }^{20}$

Table 5

\begin{tabular}{|l|c|c|c|c|}
\hline \multirow{2}{*}{ Study } & \multirow{2}{*}{ Year } & \multicolumn{2}{|c|}{ Mean PDW (fL) } & \multirow{2}{*}{ P value } \\
\cline { 3 - 4 } & & STEMI & NSTEMI & \\
\hline Salim et al $^{87}$ & 2013 & $21.5 \pm 1.7$ & $21.9 \pm 0.6$ & 0.58 \\
\hline Manchanda et al $^{20}$ & 2015 & $13.66 \pm 3.55$ & $13.24 \pm 3.46$ & $>0.05$ \\
\hline Patil et al $^{90}$ & 2017 & $13.92 \pm 1.57$ & $12.84 \pm 1.54$ & 0.001 \\
\hline Present study & $\mathbf{2 0 1 7}$ & $\mathbf{1 2 . 0 7} \pm \mathbf{1 . 6 8}$ & $\mathbf{1 2 . 0 5} \pm \mathbf{1 . 7 6}$ & $\mathbf{0 . 9 7}$ \\
\hline
\end{tabular}


P-LCR and MI Subgroups: Mean P-LCR of STEMI and NSTEMI patients were $28.55 \pm 6.07$ and $27.47 \pm$ 5.11 , respectively with no significant difference $(\mathrm{p}$ value -0.49 ). This finding was further supported by Manchanda et al. ${ }^{2}$

\section{Conclusion}

The present study showed a significantly higher MPV, PDW and P-LCR in CAD patients. MI patients had significantly higher platelet indices than stable CAD patients.

Platelet indices can be used as simple and cost effective predictive parameters with other laboratory tests in the emergency department (particularly in remote centres and where cardiac serum markers are not readily available) to predict the development of acute coronary events.

Use of platelet indices in future studies of risk stratification system to predict MI as well as in response to intervention are also worthy of consideration.

\section{References}

1. Prabhakaran D, Yusuf S, Mehta S, Pogue J, Avezum A, Budaj A, et al. Two year outcomes in patients admitted with non-ST elevation acute coronary syndrome: results of the OASIS registry 1 and 2. Indian Heart J. 2005;57:217-25.

2. Shaukat N, Lear J, Lowy A, Fletcher S, de Bono DP, Woods KL. First myocardial infarction in patients of Indian subcontinent and European origin: comparison of risk factors, management, and long-term outcome. $B M J$. 1997;314:639-42.

3. Tan AT, Emmanuel SC, Tan BY, Teo WS, Chua TS, Tan BH. Myocardial infarction in Singapore: a nationwide 10year study of multiethnic differences in incidence and mortality. Ann Acad Med Singapore. 2002;31:479-86.

4. Jose VJ, Gupta SN. Mortality and morbidity of acute ST segment elevation myocardial infarction in the current era. Indian Heart J. 2004;56:210-14.

5. Mak KH, Chia KS, Kark JD, Chua T, Tan C, Foong BH, et al. Ethnic differences in acute myocardial infarction in Singapore. Eur Heart J. 2003;24:151-60.

6. Xavier D, Pais P, Devereaux PJ, Xie C, Prabhakaran D, Reddy KS, et al. Treatment and outcomes of acute coronary syndromes in India (CREATE): a prospective analysis of registry data. Lancet. 2008;371(9622):143542.

7. Singh RB, Mengi SA, Xu T-J, Arneja AS, Dhalla NS. Pathogenesis of atherosclerosis: A multifactorial process. Experimental and Clinical Cardiology. 2002;7(1):40-53.

8. Jabeen F, Fawwad A, Rizvi H. Role of platelet indices, glycemic control and hs-CRP in pathogenesis of vascular complications in type-2 diabetic patients. Pak J Med Sci. 2013;29(1):152-6.

9. Kodiatte T, Rao S, Manikyam U, Reddy M, Lakshmaiah $\mathrm{V}$, Jagadish $\mathrm{T}$, et al. Mean platelet volume in type 2 diabetes mellitus. Journal of Laboratory Physicians. 2012;4(1):5.

10. Kasper DL. Harrison's principles of Internal Medicine, McGraw Hill, 19th edition, 2015.

11. Kumar V, Fausto N, Abbas A. Robbins and Cotran pathologic basis of disease. Saunders, Philadelphia, $\mathrm{Pa}$, USA, 9th edition, 2014.
12. Duran M, Gunebakmaz O, Uysal O, Ocak A, Yilmaz Y, Arinc $\mathrm{H}$ et al. The relation between mean platelet volume and coronary collateral vessels in patients with acute coronary syndromes. Journal of Cardiology. 2013;61(4):295-298.

13. Cohen M, Rentrop K. Limitation of myocardial ischemia by collateral circulation during sudden controlled coronary artery occlusion in human subjects: a prospective study. Circulation. 1986;74(3):469-476.

14. Fukai M, Ii M, Nakakoji T, Kawakatsu M, Nariyama J, Yokota N. Angiographically demonstrated coronary collaterals predict residual viable myocardium in patients with chronic myocardial infarction: a regional metabolic study. J Cardiol. 2000;35103-11.

15. Sabia P, Powers E, Ragosta M, Sarembock I, Burwell L, Kaul S. An Association between Collateral Blood Flow and Myocardial Viability in Patients with Recent Myocardial Infarction. New England Journal of Medicine. 1992;327(26):1825-1831.

16. Prêtre R, Rickli H, Ye Q, Benedikt P, Turina M. Frequency of collateral blood flow in the infarct-related coronary artery in rupture of the ventricular septum after acute myocardial infarction. The American Journal of Cardiology. 2000;85(4):497-499.

17. G. Ranjani, S. Manikandan, I. Rohini, S. Kalaiselvi. A study on platelet volume indices in acute coronary syndrome. IAIM. 2016;3(8):146-152.,

18. Deepshikha Sharma, Manju Pandey, J. P Rishi. A Study of platelet volume indices in patients of coronary artery diseases. Journal of Scientific and Innovative Research. 2016;5(5):161-164.

19. Khandekar M. Platelet volume indices in patients with coronary artery disease and acute myocardial infarction: an Indian scenario. Journal of Clinical Pathology. 2006;59(2):146-149.

20. Jaya Manchanda*, R M Potekar, Sharan Badiger, Abhishek Tiwari. The study of platelet indices in acute coronary syndromes. Annals of Pathology and Laboratory Medicine. 2015;2(1):A30-35.

21. Martin JF, Bath PM, Burr ML. Influence of platelet size on outcome after MI. Lancet. 1991;338:1409-1411.

22. Hadadi L, Sus I, Lakatos E, Serban R, Scridon A, Demjen Z, et al. Platelet indices and platelet-to-lymphocyte ratio predict coronary chronic total occlusion in patients with acute ST-elevation myocardial infarction. Revista Romana de Medicina de Laborator. 2015;23(4).

23. Lievens D, von Hundelshausen P. Platelets in atherosclerosis. Thromb Haemost. 2011;106(6):827-36.

24. Bizzozero J. Ueber einen neuen Formbestandtheil des Blutes und dessen Rolle bei der Thrombose und der Blutgerinnung. Archiv für Pathologische Anatomie and Physiologie und für Klinische Medicin. 1882;90(2):261332.

25. Hanson, SR and SJ Slichter. "Platelet kinetics in patients with bone marrow hypoplasia: evidence for a fixed platelet requirement." Blood 66, no. 5 (1985):1105-1109. Accessed September 29, 2017. http://www.bloodjournal.org/content/66/5/1105.

26. Spaet TH. Progress in Hemostasis and Thrombosis. Volume 2. New York: Grune \& Stratton, 1974.

27. Slichter S. Relationship between platelet count and bleeding risk in thrombocytopenic patients. Transfusion Medicine Reviews. 2004;18(3):153-167.

28. Sim X, Poncz M, Gadue P, French D. Understanding platelet generation from megakaryocytes: implications for in vitro-derived platelets. Blood. 2016;127(10):12271233. 
29. 29. White J, Krumwiede M, Escolar G. Glycoprotein Ib Is Homogeneously Distributed on External and Internal Membranes of Resting Platelets. The American Journal of Pathology. 1999;155(6):2127-2134.

30. Rendu F, Brohard-Bohn B. The platelet release reaction: granules' constituents, secretion and functions. Platelets. 2001;12(5):261-273.

31. Blair P, Flaumenhaft R. Platelet $\alpha$-granules: Basic biology and clinical correlates. Blood Reviews. 2009;23(4):177-189.

32. Israels SJ, Gerrard JM, Jacques YV, McNicol A, Cham $\mathrm{B}$, Nishibori $\mathrm{M}$, et al. Platelet dense granule membranes contain both granulophysin and P-selectin (GMP-140). Blood. 1992;80(1):143-152.

33. Merten M and Thiagarajan P. P-selectin expression on platelets determines size and stability of platelet aggregates. Circulation. 2000;102(16):1931-6.

34. Merten M and Thiagarajan P. P-selectin in arterial thrombosis. Z Kardiol. 2004;93: 855-63.

35. Dubois C, Panicot-Dubois L, Gainor J, Furie B, Furie B. Thrombin-initiated platelet activation in vivo is vWF independent during thrombus formation in a laser injury model. Journal of Clinical Investigation. 2007;117(4):953-960.

36. Padilla A. P-selectin anchors newly released ultralarge von Willebrand factor multimers to the endothelial cell surface. Blood. 2004;103(6):2150-2156.

37. Romo GM, Dong JF, Schade AJ, Gardiner EE, Kansas GS, Li CQ, et al. The glycoprotein Ib-IX-V complex is a platelet counterreceptor for P-selectin. The journal of experimental medicine. 1999;190:803-814.

38. Merten M, Beythien C, Gutensohn K, Kuhnl P, Meinertz T, Thiagarajan P. Sulfatides activate platelets through Pselectin and enhance platelet and platelet-leukocyte aggregation. Arterioscler Thromb Vasc Biol. 2005;25:258-263.

39. Niiya K, Hodson E, Bader R, Byers-Ward V, Koziol JA, Plow EF, et al. Increased surface expression of the membrane glycoprotein IIb/IIIa complex induced by platelet activation. Relationship to the binding of fibrinogen and platelet aggregation. Blood. 1987;70:475483.

40. Bennett JS. Structure and function of the platelet integrin alphaIIbbeta3. J Clin Invest. 2005;115:3363-3369.

41. Farndale RW, Lisman T, Bihan D, Hamaia S, Smerling CS, Pugh N, et al. Cell collagen interactions: the use of peptide Toolkits to investigate collagenreceptor interactions. Biochem Soc Trans. 2008;36:241-250.

42. Guidetti GF, Bernardi B, Consonni A, Rizzo P, Gruppi C, Balduini $\mathrm{C}$, et al Integrin alpha2beta1 induces phosphorylation-dependent and phosphorylation independent activation of phospholipase $\mathrm{C}$ gamma2 in platelets: role of Src kinase and Rac GTPase. J Thromb Haemost. 2009;7:1200-1206.

43. Arthur JF, Dunkley S, Andrews RK. Platelet glycoprotein VI-related clinical defects. Br J Haematol. 2007;139:363372.

44. Kahn ML, Nakanishi-Matsui M, Shapiro MJ, Ishihara H, Coughlin SR. Protease-activated receptors 1 and 4 mediate activation of human platelets by thrombin. J Clin Invest. 1999;103:879-887.

45. Price MJ. Bedside evaluation of thienopyridine antiplatelet therapy. Circulation. 2009;119:2625-2632.

46. Murugappan S, Shankar H, Kunapuli SP. Platelet receptors for adenine nucleotides and thromboxane A2. Semin Thromb Hemost. 2004;30:411-418.
47. Nakahata N. Thromboxane A2: physiology/pathophysiology, cellular signal transduction and pharmacology. Pharmacol Ther. 2008;118:18-35.

48. Dudzinski DM, Igarashi J, Greif D, Michel T. The regulation and pharmacology of endothelial nitric oxide synthase. Annu Rev Pharmacol Toxicol. 2006;46:235276.

49. Kubes P, Suzuki M, Granger DN. Nitric oxide: an endogenous modulator of leukocyte adhesion. Proc Natl Acad Sci USA. 1991;88:4651- 4655.

50. Gryglewski RJ. Prostacyclin among prostanoids. Pharmacol Rep. 2008;60:3-11.

51. Mitchell JA, Ali F, Bailey L, Moreno L, Harrington LS. Role of nitric oxide and prostacyclin as vasoactive hormones released by the endothelium. Exp Physiol. 2008;93:141-147.

52. Higgs EA, Higgs GA, Moncada S, Vane JR. Prostacyclin (PGI2) inhibits the formation of platelet thrombi in arterioles and venules of the hamster cheek pouch. $\mathrm{Br} \mathrm{J}$ Pharmacol. 1978;63:535-539.

53. Marcus AJ, Broekman MJ, Drosopoulos JH, Olson KE, Islam N, Pinsky DJ, et al. Role of CD39 (NTPDase-1) in thromboregulation, cerebroprotection, and cardioprotection. Semin Thromb Hemost. 2005;31:234246

54. Fung CY, Marcus AJ, Broekman MJ, Mahaut-Smith MP. P2X(1) receptor inhibition and soluble CD39 administration as novel approaches to widen the cardiovascular therapeutic window. Trends Cardiovasc Med. 2009;19:1-5.

55. Reitsma S, Slaaf DW, Vink H, van Zandvoort MA, oude Egbrink MG. The endothelial glycocalyx: composition, functions, and visualization. Pflugers Arch. 2007;454:345-359

56. Jabeen F, Fawwad A, Rizvi H, Alvi F. Role of platelet indices, glycemic control and hs-CRP in pathogenesis of vascular complications in type-2 diabetic patients. Pak $J$ Med Sci. 2013;29(1):152-6.

57. Agrawal BK, Manchanda B, Garg A, Mittal A, Mahajan NC, Agrawal U. Mean platelet volume in acute myocardial infarction: a case-controlled study. Journal of Cardiovascular Research. 2015;1:4.

58. Reddy K. S. Cardiovascular disease in non-Western countries. N Engl J Med. 2004;350:2438-40.

59. Sysmex XN 1000. Laboratory Procedure Manual.

60. Abass AE. Reference Value of Platelets Count and Indices in Sudanese Using Sysmex KX-2. International Journal of Healthcare Sciences. 2015;3(2):120125.

61. Sysmex XN 1000.Instructions for use, technical information- chapter 15; revised August 2015.

62. Dastjerdi M. Mean platelet volume measurement, EDTA or citrate? Hematol. 2006;11(5-6):142-5.

63. Liu S, Ren J, Han G, Wang G, Gu G, Xia Q, Li J. Mean platelet volume: a controversial marker of disease activity in Crohn's disease. European Journal of Medical Research. 2012;5:17-27.

64. Martyn CN, Matthews DM, Popp-Snijders C, Tucker J, Ewing DJ, Clarke BF. Effects of sorbinil treatment on erythrocytes and platelets of persons with diabetes. Diabetes Care. 1986;9:36-9.

65. Vagdatli E, Gounari E, Lazaridou E, Katsibourlia E, Tsikopoulou F, Labrianou I. Platelet distribution width: a simple, practical and specific marker of activation of Coagulation. Hippokratia. 2010;14(1) 28-32.

66. Shah PK. Inflammation and plaque vulnerability. Cardiovasc Drugs Ther. 2009;23:31-40.

67. Essler M, Retzer M, Bauer M, Zangl KJ, Tigyi G, Siess W. Stimulation of platelets and endothelial cells by 
mildly oxidized LDL proceeds through activation of lysophosphatidic acid receptors and the Rho/Rho-kinase pathway. Inhibition by lovastatin. Ann N Y Acad Sci. 2000;905:282-286.

68. Salim R Hamudi Al-Obeidi, Saad H Ahmedm, Fatma A Obeid. Evaluation of Platelet Indices in Patients with Acute Coronary Syndrome. Mustansiriya Medical Journal. 2013;12(1):58-64.

69. Thomas J. Kunicki, Shirley A. Williams, Diane J. Nugent, Mark Yeager. Mean Platelet Volume and Integrin Alleles Correlate with Levels of Integrins alpha IIb beta 3 and alpha 2 beta 1 in Acute Coronary Syndrome Patients and Normal Subjects. Arterioscler Thromb Vasc Biol. 2012;32:147-152.

70. Alok Ravindra Amraotkar, David Day Song, Diana Otero, Patrick James Trainor, Imtiaz Ismail, Vallari Kothari, et al. Clin Appl Thromb Hemost. Author manuscript; available in PMC 2017 August 27.

71. Sait Demirkol, Sevket Balta, Murat Unlu, Uygar Cagdas Yuksel, Turgay Celik, Zekeriya Arslan, et al. Evaluation of the mean platelet volume in patients with cardiac syndrome X. Clinics. 2012;67(9):1019-1022.

72. Ranjith MP, Divya R, Mehta VK, Krishnan MG, Kamal Raj R, Kavishwar A. Significance of platelet volume indices and platelet count in ischaemic heart disease. $J$ Clin Pathol. 2009;62:830-3.

73. Özlü F, Öztürk S, Ayhan SS, Tosun M, Alçelik M, Erdem A, et al. Predictive value of mean platelet volume in young patients with non-ST-segment elevation acute coronary syndromes: a retrospective observational study. Anadolu Kardiyol Derg. 2013;13:57-61.

74. Lippi G, Filippozzi L, Salvagno GL. Increased mean platelet volume in patients with acute coronary syndromes. Arch Pathol Lab Med. 2009;133(9):14411443.

75. Senaran H, Ileri M, Altinbas A, Kosar A, Yetkin E, Oztürk M, et al. Thrombopoietin and mean platelet volume in coronary artery disease. Clin Cardiol. 2001;24:405-8.

76. Ahamed H, Henry RA, Pai R. Association of mean platelet volume and acute coronary syndrome. Int $J$ Res Med Sci. 2017;5(4):1-4.

77. Kurtul A, Yarlioglues M, Murat SN, Celik IE, Demircelik MB, Ocek AH, et al. Predictors of Chronic Total Occlusion in Nonculprit Artery in Patients with Acute Coronary Syndrome: Mean Platelet Volume and Uric Acid. Angiology. 2015;66(6):553-9.

78. Balli M, Taşolar H, Çetin M, Cagliyan CE, Gözükara MY, Yilmaz M, et al. Relationship of platelet indices with acute stent thrombosis in patients with acute coronary syndrome. Postep Kardiol Inter. 2015;11(3):224-229.

79. Chu SG, Becker RC, Berger PB, Bhatt DL, Eikelboom JW et al. Mean platelet volume as a predictor of cardiovascular risk: a systematic review and meta analysis. J Thromb Haemost. 2010;8:148-56.

80. Khode V, Sindhur J, Kanbur D, Ruikar K, Nallulwar S. Mean platelet volume and other platelet volume indices in patients with stable coronary artery disease and acute myocardial infarction: a case control study. J Cardiovasc Dis Res. 2012;3(4):272-275.

81. Yaghoubi A, Golmohamadi Z, Alizadehasl A, Azarfarin R. Role of platelet parameters and haematological indices in myocardial infarction and unstable angina. J Pak Med Assoc. 2013;63(9):1133-1137.

82. S Ayhan, S Ozturk, A Erdem, M Ozlu, T Memioglu, M Ozyasar et al. Hematological parameters and coronary collateral circulation in patients with stable coronary artery disease. Exp Clin Cardiol. 2013;18(1):12-15.

83. D Sahin, M Gur, Z Elbasan, A Yıldırım, R Akıllı, N Koyunsever, et al. Mean Platelet Volume Associated With Aortic Distensibility, Chronic Inflammation, and Diabetes in Patients With Stable Coronary Artery Disease. Clinical and Applied Thrombosis/Hemostasis. 2014;20(4):416-421.

84. Sha li, Zhu CG, Guo Y, Xu R, Zhang Y. The relationship between theplasma PCSK9 levels and platelet indices in patients with stable coronary artery disease. $J$ Atheroscler Thromb. 2015;22:76-84.

85. R Badiger, A Hosalli, Ashwin S, Dinesha SV, Abhishek, Vijayalakshmi. Platelet indices in patients of acute coronary syndrome patients in tertiary care hospital. International Journal of Applied Research. 2015;1(13):731-734.

86. Ahamed H, Henry RA, Pai R. Association of mean platelet volume and acute coronary syndrome. Int J Res Med Sci. 2017;5(4):1-4.

87. M Orak, M Üstündag, C Gülog lu, Ö Alyan, MB Sayhan. The Role of Serum D-dimer Level in the Diagnosis of Patients Admitted to the Emergency Department Complaining of Chest Pain. The Journal of International Medical Research. 2010;38:1772 -177987.

88. Rifat EU, Yokusoglu M, Kirilmaz A, Nevruz O, Baysan $\mathrm{O}$, Kilicaslan F, et al. Mean platelet volume in St elevation and non-ST elevation myocardial infarction. Gulhane Tip Derg. 2011;53:114-118.

89. Patil KS, Karchi SD. A comparative study of platelet indices in acute coronary syndrome. International Journal of Contemporary Medical Research. 2017;4(3):657-660.

How to cite this article: Gururajaprasad. C, Kaneria I. M, Akkamahadevi P, Mahadevappa M. Comparative study of platelet indices in coronary artery diseases. Indian $\mathbf{J}$ Pathol Oncol. 2018;5(4):580-586. 